\title{
Foreword to the Special Issue on the Computational Kinematics Conference, CK2017
}

\section{Med Amine Laribi*, Giuseppe Carbone $\dagger$}

\author{
* Poitiers, France \\ $\dagger$ Rende, Italy
}

Computational Kinematics is a wide field of science addressing applications ranging from robotics to mechanics, computer science, mathematics and computer graphics.

This special issue is associated with the IFToMM 7th International Workshop on Computational Kinematics (CK2017) that took place on May 22 to 24, 2017, at Futososcope-Poitiers, France. The workshop was chaired by Said Zeghloul (University of Poiters, France) and Lotfi Romdhane (American University of Sharjah, United Arab Emirates) under the sponsorship of IFToMM and PPRIME Institute University of Poitiers, France. Local Arrangement chairs were Med Amine Laribi and Jean Pierre Gazeau at University of Poitiers.

CK2017 is one of the main activities of the IFToMM Technical Committee for Computational Kinematics. It was the seventh event of a series that started in 1993 as a specific conference series on Computational Kinematics. The first was held at the International Conference and Research Center for Computer Science (IBFI), Germany, in October 1993; the second was held at INRIA Sophia Antipolis, France, in September 1995; the third was held in Seoul, South Korea, 2001; the fourth was held at the University of Cassino, Italy, in May 2005; the fifth was held at the University of Duisburg-Essen, Germany, in May 2009; and the sixth was held in Barcelona, Spain, in May 2013.

The Proceedings of the CK2017 Workshop were published within the Springer book series on MMS, which contains 69 papers that were selected for oral presentation, after review, from 78 submissions from authors from more than 24 countries. These papers covered several aspects of computational kinematics, including kinematic design and synthesis, computational geometry in kinematics, motion analysis and synthesis, theory of mechanisms, mechanism design, kinematical analysis of serial and parallel robots, kinematical issues in biomechanics, kinematical motion analysis and simulation, geometric constraint solvers, deployable and tensegrity structures, robot motion planning, applications of computational kinematics, education in computational kinematics and theoretical foundations of kinematics, with the participation of invited plenary lectures that were delivered by Professor Doina Pisla from University of Cluj-Napoca, (Romania) and Professor Jean-Pierre Merlet from INRIA (France).

The members of the International Scientific Committee for CK Workshops are gratefully acknowledged for cooperating enthusiastically for the success of CK2017 and this special issue: Jorge Angeles (Canada), Patricia Ben-Horin (Israel), Marco Ceccarelli (Italy), Gregory Chirikjian (USA), Wang Delun (China), Raffaele Di Gregorio (Italy), Ulf Döring (Germany), Pietro Fanghella (Italy), Clément Gosselin (Canada), Just L. Herder (The Netherlands), Chintien Huang (Taiwan), Andrés Kecskeméthy (Germany), Manfred Husty (Austria), Vijay Kumar (USA), Jadran Lenarčič (Slovenia), João C. Mendes Carvalho (Brasil), Jean-Pierre Merlet (France), Leila Notash (Canada), Erica Ottaviano (Italy), Vincenzo Parenti-Castelli (Italy), Frank Park (Korea), Ian Parkin (Australia), Charles Pinto (Spain), Doina Liana Pisla (Romania), José María Rico (Mexico), Lotfi Romdhane (Tunisia-UAE), Joe Rooney (United Kingdom), Bernard Roth (USA), Jon M. Selig (United Kingdom), Moshe Shoham (Israel), Jaromír Švígler (Czech Republic), Satoshi Tadokoro (Japan), Tanio Tanev (Bulgaria), Volkert van der Wijk (The Netherlands) and Philippe Wenger (France).

The aim of this special issue is to show the activities and results from the CK community. Papers have been carefully selected under the supervision of Professor Amine Laribi, Guest Editor, not only 
on the basis of their CK2017 review scores but also on the quality of presentations. Then, each selected contributor was invited to provide a significantly extended paper, which was passed through a second careful blind peer review process by at least three external reviewers under the supervision of Professor Giuseppe Carbone, Handling Editor at Robotica. Following the reviewers' comments, authors have further improved their works in order to meet the high standards of this international journal.

We thank the authors who have contributed to this special issue for their very interesting papers in several subjects, covering many recent areas and results linked to Computational Kinematics, including the design of redundant serial spherical mechanism, ${ }^{4}$ kinetostatic analysis of tensegrity mechanism, ${ }^{5}$ type synthesis of overconstraint mechanisms, ${ }^{1}$ dynamic study of an upright unloaded walking, ${ }^{6}$ parallel manipulator analysis, ${ }^{7}$ design of haptic devices,${ }^{8}$ synthesis of planar linkages ${ }^{2}$ and finite motion in closed loop kinematics. ${ }^{3}$

As a result of the significant efforts of authors, reviewers, editors and publisher, finally, we are very pleased to share with you this selection of papers that we hope you will find valuable and inspiring towards further research and achievements in the robotics field.

\section{References}

1. T. Huang, C. Dong, H. Liu, T. Sun and D. G. Chetwynd, "A simple and visually orientated approach for type synthesis of overconstrained 1T2R parallel mechanisms," Robotica 37(7), 1161-1173 (2019).

2. Y. Wu and M. Carricato, "Workspace optimization of a class of zero-torsion parallel wrists," Robotica 37(7), 1174-1189 (2019).

3. J. J. de Jong, A. Müller and J. L. Herder, "Higher-order Taylor approximation of finite motions in mechanisms," Robotica 37(7), 1190-1201 (2019).

4. C. A. Nelson, M. A. Laribi and S. Zeghloul, "Multi-robot system optimization based on redundant serial spherical mechanism for robotic minimally invasive surgery," Robotica 37(7), 1202-1213 (2019).

5. P. Wenger and D. Chablat, "Kinetostatic analysis and solution classification of a class of planar tensegrity mechanisms," Robotica 37(7), 1214-1224 (2019).

6. H. Lamine, L. Romdhane and S. Bennour, "Parametric dynamic analysis of walking within a cable-based gait trainer," Robotica 37(7), 1225-1239 (2019).

7. A. Nayak, S. Caro and P. Wenger, "Kinematic analysis of the 3-RPS-3-SPR series-parallel manipulator," Robotica 37(7), 1240-1266 (2019).

8. C. Préault, H. Saafi, M. A. Laribi and S. Zeghloul, "Optimal design and evaluation of a dexterous 4 DoFs haptic device based on delta architecture," Robotica 37(7), 1267-1288 (2019). 